Received: December 2, 2017

\title{
Research on the Reform of Juristic Practical Teaching under Mongolian-Chinese Bilingual Mode*
}

\author{
Shue $\mathrm{Fu}^{1}$ \\ Inner Mongolia University for Nationalities
}

\begin{abstract}
The science of law is a discipline of high practicality. In the teaching of law, a variety of practical forms should be applied to strengthen the cultivation of the students' practical skills. Under the Mongolian-Chinese bilingual mode, the juristic practical teaching needs constant innovation, comprehensive use of juristic case teaching, moot court and legal clinic, as well as establishing a Mongolian-Chinese bilingual juristic practical teaching base, and other methods to change the teaching concepts, optimize the practical teaching faculty, pay attention to connotation management and continuously improve students' juristic practical skills.
\end{abstract}

\section{Keywords}

Case Teaching $\bullet$ Moot Court $\bullet$ Legal Clinic

\footnotetext{
* This paper is a phased achievement of the educational and teaching research project of Inner Mongolia University for Nationalities, "Research on the Reform of Juristic Practical Bilingual Teaching under Mongolian-Chinese" (YB2018030).

${ }^{1}$ Correspondence to: College of Politics Law and History, Inner Mongolia University for Nationalities, Tong Liao 028043, China. Email: 492348199@qq·com
} 
The science of law is a discipline of high practicality, however, under the traditional teaching mode of conceptual jurisprudence in the civil law system, the curriculum setting of juristic courses is basically in the knowledge-feeding pattern. Students memorize the concepts and theories by rote, while their hands are tied in face of practice. In view of this, the Excellent Legal Talents Education and Training Program jointly implemented by the Committee of Political and Legislative Affairs, CCCPC, and the Ministry of Education of the People's Republic of China has emphasized the need to improve the practical ability of legal talents. Jurisprudence is an important social science, its theories are extensive and profound, obscure and difficult, and its practices are intricate and complicated, changeable and varied, it is a legal subject that is hard to grasp. Therefore, juristic practical teaching becomes very important. As a minority autonomous region, in Inner Mongolia, grassroots legal talents are extremely scarce, and Mongolian legal talents are lacking. The Inner Mongolian National University for Nationalities, as a national higher education institution, should be based on the reality of the region. Under the Mongolian-Chinese bilingual mode, this paper explores the juristic practical teaching mode and reforms the bilingual teaching mode so as to cultivate bilingual talents adapted to local needs, actively transform the talent training mode, and provide a way for the cultivation of bilingual talents in other minority areas.

\section{Legitimacy of juristic practical teaching under Mongolian-Chinese bilingual mode}

Bilingual teaching mode is originally a higher education reform measure taken in order to integrate with the international community. Due to the strengthening of international social exchanges and the improvement of China's international social status, this teaching mode has become a hot spot in China's higher education teaching reform. There are three modes of bilingual teaching, namely, immersion bilingual teaching, maintenance bilingual teaching, and transitional bilingual teaching. In essence, the development of bilingual teaching mode is formulated for the integration of China and the international community. The so-called bilingualism, in a narrow sense, requires that in addition to using Chinese, a foreign language can be chosen for teaching. In a broad sense, all teaching activities carried out in any language other than Chinese are included in this category; and the reforms carried out by ethnic colleges and universities in various minority areas in China are included in this category as well. The juristic bilingual teaching of Inner Mongolia University for Nationalities is based on the actual situation in the region and is conducted both in Chinese and in a minority language Mongolian. The reform of bilingual teaching mode in China has achieved certain results in colleges and universities. However, it seems that the development of bilingual teaching in various universities only stays at a theoretical level, or is only conducted from the perspective of theoretical teaching. Using two languages in classroom teaching is not enough for law majors which are of high practicality. Of course, there are many difficulties for colleges and universities to carry out bilingual practical teaching, especially for colleges and universities that use foreign language for the teaching, students are rarely exposed to actual cases. (Adu, 2013) While for ethnic colleges and universities, it is their advantage. Taking the Inner Mongolia University for Nationalities as an example, it is located in the Mongolian Autonomous Region, about two-thirds of the Mongolians live here. It is the rights of minorities to use their own ethnic language to institute proceedings. Moreover, the Mongolian-Chinese bilingual grassroots legal talents are extremely lacking. The training goal of 
the law education of Inner Mongolia University for Nationalities is to provide a large number of grassroots legal talents for the region. Therefore, Mongolian-Chinese bilingual juristic practical teaching has a unique advantage.

\section{Content of Mongolian-Chinese bilingual juristic practical teaching}

\section{Selection and application of Mongolian-Chinese bilingual juristic case teaching}

Case teaching method is an ancient teaching method, it originated from ancient Greece and was created by the famous Greek philosopher Socrates, so it's also called the Socratic teaching method. Later, Professor Randall of Harvard University combined this teaching method with the court cases and called it the case teaching method. The case teaching method has achieved great success in common law system countries. It is rooted in the legal tradition and legal culture of common law system countries, and it has changed the spoonfeeding teaching mode. In the teaching process, teachers let students analyze the case through the demonstration of a typical case, so as to achieve the purpose of teaching. This teaching method fully mobilizes the students' enthusiasm for learning, greatly enhances the enthusiasm of students, and through the analysis and answering of practical problems, it cultivates students' practical ability to solve problems. The juristic theories are profound and practical, the basic concepts and theories are abstract, and there are many terminologies. Therefore, through the method of case teaching, the juristic theories were demonstrated layer by layer from abstract to concrete, which can not only improve students' practical ability for problem analyzing and solving, but can also make students have a deeper understanding of juristic theories. Especially in ethnic colleges and universities, minority students have different cultural foundations and levels. In Inner Mongolia, many Mongolian students come from pastoral areas. They received Mongolian education from an early age. Their thinking styles and cultural traditions are very different from those of the Han nationality. The juristic textbooks are all in Chinese, so there are differences in understanding and acceptance. The introduction of the case teaching method makes the abstract theory concrete and compensates for the deviation caused by different ways of thinking.

The selection of Mongolian-Chinese bilingual juristic cases. In the application of case teaching method, the choice of case is the key to the case teaching method. In Anglo-American law system countries, they all practice the Case-law tradition, most of the selected cases are typical cases with greater influences, which still have legal effect until now. However, China does not recognize the validity of Case-law, so we need to carefully consider the selection of cases. In fact, the Supreme People's Court issues guiding cases every year. Although these cases are not binding on the lower courts like the law cases of the Anglo-American law system countries, in fact, in the judicial practice of our country, when the lower courts encounter similar problems, they will refer to these cases. Therefore, these guiding cases should be an important source of case teaching. Secondly, the use of Mongolian language for litigation and trial in Inner Mongolia is also a resource for case teaching. The courts in the Tongliao area of Inner Mongolia have many practical cases of this kind. These cases fully reflect the characteristics of the Mongolian language litigation in the region, and thus become the best choice for the Mongolian-Chinese bilingual juristic case teaching. 
The application of Mongolian-Chinese bilingual juristic case teaching method. Although the application of the case teaching method has considerable advantages, this method is mostly applied to the juristic teaching process, and the content of the procedural law is not involved, so its application is also greatly limited. Generally speaking, most of the teaching is conducted by means of demonstration, comment and discussion of cases, occasionally, it can also be conducted by means of court trial attending. The demonstration case teaching method is generally applied by teachers, especially during juristic teaching, this method is used to explain juristic abstract theories and to demonstrate the specific application of the theory. The comment case teaching method is to guide the students to deeply analyze the specific problems in the case, so that the students can master the profound theoretical content in the law. The discussion case teaching method requires the students to have a certain amount of knowledge, and then the teacher selects typical cases for analysis and discussion. The implementation can take many forms, which can be either the group discussion or discussion within the whole class, but the teacher must evaluate and analyze the case at last, and explains the process of thinking to the students. This method can fully mobilize the enthusiasm of Mongolian students to study the law. The teaching method of attending the court trail of typical cases actually makes students have a more intuitive understanding of legal knowledge. In recent years, the law majors of Inner Mongolia University for Nationalities have continuously organized students to attend the courts, and even invited the court to the moot court of the school to conduct trials of actual cases. It stimulated students' interest in learning and improved their ability to think independently.

\section{Implementation of moot court.}

In the law education in China, the moot court teaching mode is a commonly used method for cultivating students' practical abilities. It originated in the United States and was introduced to China in the 1930s. In recent years, it has been increasingly valued and favoured by law education in colleges and universities. In the process of juristic teaching, an open teaching method is adopted, and typical juristic cases are selected, and a complete case hearing procedure is presented under the guidance of the instructor. Before the court session, students are required to prepare the litigation documents carefully, go over the words of the statement and the defence opinions repeatedly, and make full preparation for the moot court. In the trial, requirements of procedures and steps must be strictly followed, and must not be simplified optionally. After the trial, the instructor should carefully summarize and analyze and give guidance from the two aspects of procedural law and substantial law, especially, the instructor should also give profound analysis and point out shortcomings from the perspective of juristic theories. By simulating the judges, presiding judges, lawyers and even clerks of the court, students can actively discuss and explore case handling skills, seek the application of law and study relevant cases, so that theory and practice are combined together, which can deepen the understanding and mastering of the juristic knowledge, as well as improve students' practical abilities. 


\section{Setting of legal clinics.}

The cultivation of law school students requires students to have a solid theoretical foundation and strong practical abilities. "When finishing the professional education, law school students should be equipped with legal awareness, position and skills they should have". (Chen \& Zhao, 2000) China's traditional law education pays too much attention to the teaching of theoretical knowledge, while ignoring the cultivation of students' practical abilities. Jerome Frank, an American judge, one of the major representatives of the realist law school, once said: "Legal practice and case judgment are not science, but an art, it's the art of lawyers and judges. In any art, only a small part can be learned from books, whether it is painting, writing or legal practice. The best way to teach an art is usually the apprentice-style training under the guidance of highly skilled people in this art practice." (Frank, 1993) The legal clinic teaching mode draws on medical school students' practical experience cultivation mode, so that students can develop their practical abilities in the process of contacting actual cases in social realities. Under the guidance of the legal clinic teachers, during receiving the parties, providing legal advice, prosecuting, responding to lawsuit and other legal procedures, this mode cultivates students' practical skills and deepens their understanding of theoretical knowledge. However, China has different legal traditions with the Anglo-American legal system, and the setting up of legal clinics in China must take the specific national conditions into considerations. The legal clinic should belong to the advanced course of juristic teaching. It should be carried out after the completion of the study of the basic knowledge of law, such as civil law, property law, contract law, intellectual property law, commercial law, marriage and family law and tort liability law. As for the selection of instructors, besides having a high level of research ability and a solid theoretical foundation, also they should be equipped with considerable judicial practice experience. Generally speaking, in the process of initially introducing legal clinic education in China, the instructors are part-time teachers who are also teachers in the school, but from the current point of view, the effect is not satisfactory. According to the national Excellent Legal Talents Education and Training Program, the barrier between the juristic theory field and practice field should be broken, and the interaction between the two will become increasingly frequent. At this time, the legal clinic should hire experts from the practice field to serve as instructors, such as judges and lawyers with many years of trial experiences in civil trials. In Inner Mongolia, we should also focus on hiring judges and lawyers who can use both Mongolian and Chinese for the civil lawsuits, in this way, it can complement each other's advantages, broaden students' vision, and achieve good teaching results.

\section{Construction of the Mongolian-Chinese bilingual practical teaching base.}

At present, there is an urgent need for a large number of Mongolian-Chinese bilingual legal workers in Inner Mongolia. However, during the undergraduate stage of the law major, due to the setting of legal courses in advanced education, it is difficult for students to get effective training for their practical skills. Even in ordinary civil disputes, graduated students often appeared ignorant and didn't know where to begin with. In view of the unsatisfactory effect of juristic practical teaching, Inner Mongolia University for Nationalities has reformed the juristic teaching mode. In order to meet the needs of students' graduation internships, it has established cooperative relations with relevant courts, procuratorates and large-scale law firms in Tongliao, Inner Mongolia, and constructed a Mongolian-Chinese bilingual juristic practical teaching base off campus. The most important 
thing for the construction of the Mongolian-Chinese bilingual juristic practical teaching base is the allocation of off-campus instructors, and only judges and lawyers who are proficient in Mongolian and Chinese bilingual can take this responsibility. According to the students' learning situation of civil law knowledge, the school will arrange for the teachers in the practice base to contact the actual cases. Due to the large number of civil cases and the close relationship with daily life, students can learn in the practice base by participating in the entire process of the case under the leading of internship unit instructors, so that their practical operation skills can be improved greatly.

\section{Shortcomings of Mongolian-Chinese bilingual juristic practical teaching}

The teaching concept is outdated and inappropriate. Traditional teaching concepts have always influenced or restricted the pace of juristic teaching reform. China's school education has been focusing on theoretical indoctrination, while concerning less about practical abilities. Although the practical characteristics of juristic education are quite prominent, still it can't reverse this kind of old teaching concept. Because law school students can't exercise their practical skills, they are far from the requirement of the society for legal talents, many graduates report that they have to learn from scratch after employment. Employers also reflect the fact that some students have two-star abilities with five-star ambitions, so some units no longer hire undergraduate students any more. Fundamentally speaking, the emergence of these problems is that our teaching concept has lagged behind the requirements of the times. Especially for the law education of colleges and universities in ethnic areas, the teaching concept must be changed, otherwise it has to be eliminated.

The curriculum setting is unreasonable and the positioning is vague. In the curriculum setting of law majors in colleges and universities in China, the juristic theoretical courses have taken a high proportion, and the courses are set in early stages, normally set in the freshman year, and there are no practical courses for law majors. That is to say, so far, the curriculum setting of law courses in colleges and universities is still biased towards theory. There are also such problems in the curriculum setting of law courses in Inner Mongolia University for Nationalities. Students are submerged in the sea of law concepts and theories, while they know nothing about legal practice. Especially for Mongolian students, it is a kind of torture to explain the abstract and vague theories in Chinese that they are not very good at.

The structure of the practical teaching faculty is not reasonable. The first prerequisite for the development of practical teaching courses is the requirements for the faculty. It not only requires teachers to have a solid and profound juristic theoretical foundation and strict legal logic thinking ability, but also requires teachers to have rich legal practice experience and skills, and the two cannot be neglected or biased. The reality of our country is that there is a clear distinction between theoretical research and judicial practice. College teachers are immersed in scientific and theoretical research, and they extremely lack of practical experience. Although our country is aware of the situation, it intends to break the invisible barrier between legal theory and legal practice, but this is not something that can be changed overnight.

It's more formalistic rather than substantial. The emphasis of law education reform in China's colleges and universities has gradually shifted to practical teaching, and in fact, colleges and universities have gradually 
recognized the practical characteristics of the discipline of law, and gradually increased the intensity of practical teaching. For example, most colleges have set up moot courts, and teachers also use case-based teaching methods in classroom teaching. However, the students' practical abilities have not been significantly improved. The reason is that many colleges and universities' juristic practical teaching is formalistic rather than substantial. In most cases, the teachers were just completing the course tasks, and didn't prepare carefully. The practice courses are just formalistic, and have no practical meaning.

\section{Improvement of Mongolian-Chinese bilingual juristic practical teaching}

Change the concept and attach importance to the cultivation of practical ability. The importance of juristic practice is self-evident. The Inner Mongolia region is in the transition period of the development of social economic law, and its demand for Mongolian-Chinese bilingual talents is quite urgent. The application of jurisprudence in practice is extensive, and its theory and practice should be complementary. As a national college, the curriculum setting of juristic practice should be combined with the local situation. But what is more important is to change from the concept and attach importance to the cultivation of practical ability. In curriculum design, we should set juristic case teaching courses, moot court courses and legal clinic courses, so that the proportion of juristic theory and practice is proper, thus we can cultivate legal professionals that are suitable for local social needs (He, 2016).

Optimize the structure of the faculty. The success of the reform of juristic practical teaching is based on whether there is a faculty with both theoretical knowledge and practical ability. For ethnic areas, there is a shortage of senior legal talents, and the possession of practical skills is by no means an overnight accomplishment. In addition, the access mechanism of the legal market is becoming more and more strict. It's not anyone with college juristic teacher qualification can engage in the legal practice. Therefore, in addition to using the existing legal talents in the school, the juristic practical faculty should also work with local legal practice departments and establish extensive cooperation and contacts with them, invite personnel of the practice department to be the instructor of the school juristic practical teaching, and form a positive interaction between colleges and the society.

Strengthen the management of Mongolian-Chinese bilingual practical teaching. The reform of practical teaching is a long-term and arduous task. There is no existing model to learn from, and it can only be explored continuously. Especially for ethnic colleges and universities, they can only keep moving forward in the process of exploration. During the implementation of Mongolian-Chinese bilingual juristic practice, it is necessary to strengthen teaching management, equip with special management personnel, increase material input, innovate practical teaching methods, sum up experience and lessons, so that juristic practical teaching is not only in form, but also emphasizes the connotation of practical teaching, thereby cultivating qualified legal talents that meet the requirements of the times for ethnic areas. 


\section{References}

Adu, Q. F. Investigation and countermeasure consideration on the employment situation of Mongolian teaching graduates. Research on Ethnic Higher Education of Nationalities, 1, 79-84, http://dx.doi.org/10.3969/j.issn.1008-5149.2013.01.017

Chen. L., Zhao, H. (2000). Teaching outline of clinical law. Journal of Wuhan University, 6, 811-814, http://dx.doi.org/10.3969/j.issn.1671-881X.2000.06.018

Frank, J. (1933). Why not a clinical lawyer-school?’(1933) 81. U Pa L Rev, 8, 907-913. http://dx.doi.org/ $10.2307 / 3308054$

He Z. L. (2016). Docking Research from Needs Game Perspective of Teacher Education and Basic Education: Taking Henan Province as an Example. Journal of Chifeng University (Philosophy and Social Sciences Edition), (2), 260-263, http://dx.doi.org/10.3969/j.issn.1673-2596.2016.02.092. 